УДК 94

М. А. Максименко

\title{
К ВОПРОСУ О СОЦИАЛЬНО-ЭКОНОМИЧЕСКИХ АСПЕКТАХ ИНДУСТРИАЛЬНОЙ РЕВОЛЮЦИИ В ШОТЛАНДИИ В ХІХ ВЕКЕ
}

Настоящая статья изучает отдельные социально - экономические аспекты индустриальной революции в Шотландии в XIX в. Актуальность исследования вопроса об индустриальной революции в Шотландии объясняется не только слабой степенью изученности, но и различными темпами ее развития по сравнению с английской. Отечественный корпус научной литературы частично освещает проблемы индустриализации в Шотландии, анализируя ее в контексте британской промышленной революции. Примечательно, что индустриальная революция в целом отличалась крайней неравномерностью и несинхронной скоростью отдельных регионов Великобритании, но, несомненно, главным итогом было достижение прогресса и улучшение условий жизни общества. В статье учитывается влияние международных отношений на формирование локального шотланд- ского рынка, природно - географический фактор, а также рост научных знаний и открытий. Основными задачами исследования является выявление особенностей развития промышленной революции в Шотландии, изучение специфики развития таких ключевых отраслей индустрии, как хлопчатобумажная, металлургическая, а также железнодорожное строительство. Более того, важной задачей является изучение влияния экономического развития на шотландское общество.

Ключевые слова: индустриализация, промышленная революция в Шотландии, хлопчатобумажная промышленность, хлопковое производство, индустриальная революция Великобритании, история Шотландии, экономическая история, социальная история, урбанизация, зарубежная история XIX века.

\section{A. Maximenko}

\section{ON SOCIO-ECONOMIC ASPECTS OF THE INDUSTRIAL REVOLUTION IN SCOTLAND IN THE XIX CENTURY}

The article studies certain socio-economic aspects of industrial revolution in Scotland in the 19th century. The topicality of industrial revolution in Scotland is explained not only by weak degree of study, but also various rates of its development as compared to the one in England. Industrialization problems in Scotland in the context of the British industrial revolution are partially highlighted in national scientific domain. It is remarkable that the industrial revolution in general differed in extreme unevenness and nonsynchronous speed of certain regions in Great Britain, but, undoubtedly, the achievement of progress and improvement of living conditions were the main outcomes. The article analyzes the influence of international relations on forming the local

В зарубежной исследовательской практике шотландская и британская промышленная революция становятся предметом отдельных трудов ученых. Эволюция взглядов на индустриализацию в последнее время претерпела
Scottish market, natural-geographic factor and also the growth of scientific knowledge and discoveries. The main objectives of the study are the identification of development features of industrial revolution in Scotland and peculiarities of development of such key industries as cotton production, metallurgy and railway construction. Moreover, an important task is to specify the influence of economic development on the Scottish society.

Key words: industrialization, industrial revolution in Scotland, cotton industry, cotton production, industrial revolution in Great Britain, history of Scotland, economic history, social history, urbanization, foreign history of the XIX century.

значительные изменения. Развитие исторического знания на рубеже $\mathrm{XX}-\mathrm{XXI}$ вв. сформировало совершенно новый подход к проблеме промышленной революции. В свою очередь, это обстоятельство способствовало смещению 
центра исследовательских практик к изучению личности в совокупности ее материальных и духовных потребностей. В трудах второй половины XX в., освещающих вопросы промышленной революции, лейтмотивом повествования является человек с его социально - бытовыми, культурными, политическими и экономическими особенностями.

Современный корпус научной литературы об индустриальной революции в Шотландии содержит анализ, как экономических аспектов развития, так и социальные проблемы исследуемого явления. Однако, существует большое количество работ, посвященных анализу отдельных отраслей промышленного производства в Шотландии. Такая исследовательская позиция не противоречит действительности, поскольку, к примеру, хлопковое производство занимало центральное место в структуре шотландской экономики.

Несомненно, в Великобритании индустриальная революция прежде всего, была связана с высокими темпами развития в хлопчатобумажной отрасли. Уже к 20-м гг. XIX в. в Англии и Шотландии работало свыше 14 тыс. ткацких станков с паровым приводом, а в середине 30-х гг. их число увеличилось до 100 тыс. [2, с. 154].

Исследовательская перспектива направлена на выявление отличительных черт английской и шотландской промышленной революции. Хлопковая промышленность строилась по мере применения новой технологии, но в значительной степени потому, что у шотландцев была успешной льняная промышленность, из которой быстро развивалась хлопковая промышленность [4, р. 38]. Эта наиболее яркая особенность, которая отличает шотландскую промышленную революцию от английской.

В центре исследовательской практики находятся вопросы международных отношений, которые оказали влияние на локальный рынок. В результате спроса, порожденного такими войнами как: Крымская, Гражданская война в Америке, Бурская и Первая мировая, которые привели к увеличению продаж и прибыли в льняной промышленности восточно-центральной Шотландии [8, р. 168]. Но периоды экономического благосостояния Шотландии сочетались с нестабильностью, которые характерны для процесса индустриальной революции в целом. Некоторые предприятия росли во время Французских войн, отсеивая мелкие компании. Основной капитал одних только прядильных фрабрик в 1812 г. оценивался в 1,4 фунтов стерлингов; к 1840 г., было установлено, что общая стоимость капи- тала всей промышленности составляла около 4,4 млн фунтов стерлингов [14, р. 26].

Мировой рынок стал еще одним важным фактором, который способствовал ускорению темпов промышленного производства. Развитие зарубежного рынка связано с успехами в судостроении и тяжелой технике, что в свою очередь зависело от наличия богатых месторождений угля и железа в центральном поясе [5, р. 38]. Несомненно, природно-географический фактор играет значимую роль в индустриальной революции. Во многом, таким темпам промышленного роста Шотландская экономика обязана богатым природным ресурсам. К. Уотли поясняет, что важное значение исследователи также придают заключению Союза 1707 г., объясняя процессы шотландской индустриализации. После 1707 г. был создан общебританский рынок, позволявший Шотландии не только свободную торговлю в Англии, но и с американскими колониями. Фокус внешней торговли Шотландии переместился из континентальной Европы в сторону быстро растущей атлантической экономики, хотя золотой век табака в значительной степени зависел от европейского благосостояния и привычки к табаку, и, в частности, предпочтения во Франции, главного клиента Глазго. Он также отмечает, что в 1840-е гг. Азия, Южная Америка и Австралазия стали важными торговыми партнерами [14, р. 39-40]. С этим соглашается и другой видный ученый Т. Девайн, подчеркивая, что между 1785 и 1835 г. экспорт вырос в 9 раз и Шотландия стала ключевым игроком на рынке Атлантики, который являлся самым быстрорастущим рынком в мире в этот период [7]. В первые десятилетия XIX в. были образованы новые шотландские торговые связи с Южной Америкой, Азией и Австралазией. В конце наполеоновских войн в 1815 году Америка и Карибский бассейн составляли почти 70 \% тоннажа, покидающего Клайд. Большая часть остального предназначалась для европейского континента [7]. Доходы же, полученные от торговли табаком, сахаром и хлопком, имели непосредственное влияние на развитие сельского хозяйства в регионах, прилегающих в Глазго [1, с. 492].

Высокий рост в хлопковой индустрии основывался на бурном спросе со стороны быстро растущего населения и наличия рабочей силы в сельских районах [11, р. 141]. Этот фракт позволяет утверждать, что для первого этапа индустриальной революции характерен медленный переход от ручного труда к машинному. 
Скорее всего, можно говорить о том, что наряду с высокими и беспрецедентными темпами технических открытий и изобретений, достаточно долго не сдавал свои позиции и ручной сектор.

Около 60 \% занятых в текстильной промышленности, приходится на производства хлопка. Лен утрачивает свою позицию к 1800 году [14, р. 26]. Ярким примером может служить производство в городе Пейсли, который традиционно специализировался на тонких льняных товарах, а с 1750-х на шелковых изделиях, а после стал производителем хлопковой продукции (с плетения искусственных индийских платков в 1803, сохраняя за собой репутацию по качеству работы) [14, p. 26]. Хорошее состояние продукции часто встречается в описаниях историков «...следует отметить превосходное качество ранних шотландских продуктов. Длительное время потребовалось для того, чтобы Глазго стал всемирным центром по изготовлению прекрасных хлопчатобумажных тканей» [12, р. 16]. На самом деле оборудования, используемые в льняной индустрии, были пригодны для обработки только грубых волокон. Но затруднение вызывало другое обстоятельство: лен содержал какое-то клейкое выделение, благодаря чему волокна склеивались, что препятствовало работе [9, р. 155]. Можно предположить, что по этой причине, переход на полное механизированное производство, был затруднен.

Другие ученые замечают, что в усовершенствованиях ранних ткацких станков имелись недостатки, которые позволяли растущему числу ткачей ручных ткацких станков поддерживать некоторую независимость и избегать полного поглощения новой заводской системой $[13$, р. 8]. К тому же ирландские иммигранты и горцы присоединились к прядильным фабрикам. Их увеличивающееся число, наконец, решило проблему трудовых ресурсов, поскольку, мельницы не могли легко привлечь грамотного шотландца из Лоуленда. Действительно, новая фабричная рабочая сила и новое городское общество на западе Шотландии покоились на неграмотных, голодных, обездоленных и иммигрантах [13, р. 8]. Мысля в этом направлении, представляется возможным говорить о том, что перемещение трудовых ресурсов из сельской местности в город, меняло и сам характер шотландского общества.

По словам Уильяма Марвика, использование энергии пара, как в ткачестве, так и в других текстильных отраслях являлось поздним и более медленным [10, р. 36]. Но, несмотря на это, именно благодаря энергии пара становится возможной всесторонняя механизация производства. В 1821 г. в Кирккальде были установлены мощные станки, а в 1824 г. - в Маберли в его абердинском заводе, жаккардовый ткацкий станок был введен в Данфермлайне примерно в 1825 г. [13, р. 36]. Шерстяная промышленность после безуспешных усилий по продвижению в XVII в., неудач в соревновании с английской в XVIII в., теперь стала процветать, особенно на границе, где местные запасы шерсти и энергия воды давали ей естественные преимущества. Рой Кэмпбелл называет 1825 г. - пиком процветания хлопковой промышленности. Именно в это время происходит переход от хлопка к железной индустрии, как ведущей отрасли экономики [10, р. 40]. К этому времени основное строительство прядильных фабрик было закончено.

С 1780-х гг. появлялись хлопковые прядильные фрабрики, и повысился импорт ваты в 1778 , более чем 200,000 фунтов; в 1788 г., более чем $1,500,000$ фунтов. Последующее расширение в производстве пряжи повышало спрос на ткачей ручного ткацкого станка, пока процесс не стал механизированным после наполеоновских войн [3, р. 42]. Наполеоновские войны оставили след в экономике многих индустриально развитых городов Шотландии. Современник Питер Кармайкл отмечал, что застой в торговле и высокая цена провизии привели к тому, что многие семьи стали жертвами голода в Данди. Местный писатель, ссылаясь на это время, отмечал, что перед Ватерлоо ткачам было выплачено двадцать шиллингов за работу сети Оснабург на 150 ярдов, но цена упала до пяти шиллингов до конца года [5, р. 13]. По словам М. Линча, в Шотландии в целом тяжелая промышленность обогнала текстиль только в 1891 году [12, р. 407]. Рой Кэмпбелл обращает внимание на то, что к 1850 году на долю Шотландии приходилось более 90 \% британского экспорта чугуна [3, p. 40]. В период между 1825 и 1841 гг. на западе Шотландии были открыты 11 новых металлургических заводов. По мнению Энтони Славена, именно запад Шотландии сформировал базу, благодаря которой процесс индустриализации мог бы поддерживаться в течение десятилетия с 1830 по 1870 г. [13, р. 8]. В 1848 году в Ланаркшире было 15 металлургических заводов с 92 печами. Шотландская железная промышленность увеличила выпуск продукции до 564000 тонн, что более чем в два раза превышает показатель на 1840 год и более чем в двадцать раз превышает выпуск 1825 года. Затраты на производство тонны 
чугуна были на 40 \% ниже показателей 1829 года. Большая часть этого быстрого роста была сосредоточена в Монклендсе, и это не удивительно. В 1840-х годах Монклендс имел легкий доступ к дешевому транспорту большой вместимости. В этом районе также обнаружены богатые и обширные ресурсы железных руд черных и глинистых металлов. Здесь также были построены первые железные дороги [13, р. 118].

B XIX в. механизация коснулась и транспорта. Создаются железные дороги, появляются станции, строятся поезда. Благодаря поддержке торговцев, около 350 трамвайных маршрутов было установлено между 1750 и 1840 гг. [5, р. 58-59]. Новые железнодорожные узлы позволили не только сократить время проезда, но и стали главными магистралями, набирающего темпы, урбанизированного общества.

Период промышленного подъема совпал с ростом населения, причем городского. Примечательно, что шотландские статистические отчеты не всегда содержат объективные данные. Причем разница существует не только в источниках, созданных в Шотландии, но и в британской статистике, включающей данные численности шотландского населения. Но, несмотря на статистические неточности, очевидно, что к XIX в. такие крупные города, как Эдинбург, Глазго, Абердин, Данди являлись крупно населенными городскими центрами.

Исследуя запатентованные открытия и изобретения, становится очевидным обстоятельство, что с каждым годом количество открытий увеличивалось не только в количественном отношении, но и в разнообразии сфрер использования. Больше всего открытий в начале XIX в. приходилось на сфреру текстильного производства, что неслучайно. Тогда именно лен и хлопок находились в основе экономического развития Шотландии. Стоит отметить заслугу таких шотландских ученых, как Дж. Уатт, Ч. Теннант, Т. Телфорд, Д. Ренни, Ч. Макинтош, Дж. Нейлсон без которых не представляется возможным изучение феномена индустриальной революции в целом. Все чаще появляющиеся открытия и изобретения часто дублирова- ли уже имеющиеся, а другие ученые и вовсе были вынуждены снова и снова доказывать свое авторство. Это в первую очередь связано с неразвитостью патентного законодательства, а также со слабостью международного научного обмена. При этом, стоит помнить, что шотландские ученые открыли миру большое количество изобретений. К примеру, стоит отметить положительный вклад в промышленную химию в XVIII в., в отрасли машиностроения и строительства в XIX [4, p. 38].

Социально-экономические особенности Шотландской революции связаны не только с высокими темпами производства во всех сферах экономики Шотландии, но и с изменением структуры общества. Благодаря накоплению капитала среди торговцев, они могли позволить себе лучшие условия жизни и совершенно иную структуру потребления. Наиболее зажиточные представители этой отрасли, были крупнейшими инвесторами своей эпохи. Другие же, такие как рабочий класс, который стояли у истоков этого «экономического чуда» едва ли могли похвастаться удовлетворительными условиями существования. В целом, можно говорить о разных следствиях промышленной революции, но, скорее всего, важнейшим из них являлось формирование общества нового времени.

Таким образом, социально-экономические особенности индустриализации в Шотландии в XIX в. демонстрировали высокие темпы промышленного производства, особенно в хлопчатобумажной отрасли экономики, которая долгое время переживала бурный экономический рост. Не менее активными отраслями экономики являлись металлургическая и машиностроительная. Благодаря росту новых производственных центров, решался вопрос о рабочих местах. Другой важной особенностью являлась высокая степень адаптации общества к динамике внутреннего рынка и меняющимся условиям жизни. Так, и социальные, и экономические результаты промышленной революции были центральными векторами ее развития.

\section{Источники и литература / References}

1. Апрыщенко В. Ю. Шотландия в Новое время: в поисках идентичностей. СПб.: Алетейя, 2016.720 с.

Apryshchenko V. Yu. Shotlandiya v Novoe vremya: v poiskakh identichnostey (Scotland in Modern period: In search of identities). St. Petersburg: Aleteyya, 2016. 720 p. (In Russian)

2. Виргинский В. С. Очерки науки и техники XVI-XIX. М.: Просвещение, 1984. 287 с.

Virginskiy V. S. Ocherki nauki i tekhniki XVI-XIX (Essays on science and technology). Moscow: Prosveshchenie, 1984. 287 p. (In Russian)

3. Campbell R. H. The Industrial Revolution: A Revision Article // The Scottish Historical Review. Vol. 46. No. 141. Part 1. April. 1967. P. 40-42.

4. Campbell R. H. The Rise and Fall of Scottish Industry 1707-1939. Edinburgh, 1980. 18 p. 
5. Carmichael P., Gauldie E. The Dundee textile industry, 1790-1885: from the papers of Peter Carmichael of Arthurstone. Edinburgh, 1969. P. 13-59.

6. Carmichael P., Gauldie E. The Dundee textile industry, 1790-1885: from the papers of Peter Carmichael of Arthurstone. Edinburgh, 1969. 278 p.

7. Devine T. M. The Scottish Nation: A Modern History URL: https://books.google.ru/books?id=HBW-6peFSU4C\&pg=PT1 $61 \& d q=$ trade+industry+scotland\&hl=ru\&sa=X\&ved=0ahUKEwjLoNDA4KzVAhWBK5oKHQTHDAg4HhDoAQgtMAE\#v=onep age\&q=key\&f=false (Accesssed: 28.07.17)

8. Durie A. J. The Scottish Linen Industry in the Eighteenth Century. Jonh Donald Publishers LTD. Edinburgh, 1979. P.168

9. Hamilton H. An Economic History of Scotland in the eighteen century. Clarendon press. Oxford, 1963. 452 p.

10. Marwick W. H. Scotland in Modern Times: An Outline of Economic and Social Development science the Union of the 1707. London and Edinburg, 1964. P.36

11. Scottish capitalism. Class, State and Nation from the Union to the Present. Ed. by T. Dickson. London, 1980. 335 p.

12. Scottish industry. An account of what Scotland makes and where she makes it /ed.by Oakley C.A. The Scottish council., 1953. 332 p.

13. Slaven A. The Development of the West of Scotland 1750 - 1960. London and Boston, 1975. P. 8, 118

14. Whatley C. A. The Industrial Revolution in Scotland. Cambridge University press, 1997. P. 25-40. 